\title{
Erratum to: A PKS I gene-based screening approach for the discovery of a new polyketide from Penicillium citrinum Salicorn 46
}

\author{
Xiaomin Wang $\cdot$ Hui Wang $\cdot$ Tianxing Liu $\cdot$ Zhihong Xin
}

Published online: 4 April 2014

(C) Springer-Verlag Berlin Heidelberg 2014

Erratum to: Appl Microbiol Biotechnol

DOI 10.1007/s00253-014-5572-3

In the original publication, Table 2 was incorrectly presented.

Please see below for the correct presentation.

Table 2 Antimicrobial activity of the compounds isolated from P. citrinum

\begin{tabular}{|c|c|c|c|c|c|c|c|c|c|}
\hline \multirow[t]{2}{*}{ Tested strains } & \multicolumn{9}{|c|}{$\operatorname{MIC}(\mu \mathrm{M})$} \\
\hline & 1 & 2 & 3 & 4 & 5 & 6 & 7 & 8 & Gentamicin \\
\hline E. coli & - & - & - & - & - & - & - & - & $14 \pm 0.37$ \\
\hline C. albicans & - & $25.5 \pm 0.48$ & - & - & - & - & - & - & $7 \pm 0.69$ \\
\hline B. subtilis & - & - & - & - & $22.5 \pm 0.45$ & - & - & - & $28 \pm 0.55$ \\
\hline S. aureus & - & - & - & - & - & - & - & - & $28 \pm 0.45$ \\
\hline C. perfringens & - & $25.5 \pm 0.25$ & $23.5 \pm 0.42$ & - & - & - & - & - & $14 \pm 0.42$ \\
\hline M. tetragenus & - & - & $23.5 \pm 0.38$ & - & - & - & - & - & $14 \pm 0.58$ \\
\hline M. smegmatis & - & $18.5 \pm 0.34$ & - & - & - & - & - & - & $14 \pm 0.38$ \\
\hline M. phlei & - & $51.0 \pm 0.68$ & - & $23.4 \pm 0.36$ & - & $14.4 \pm 0.34$ & - & - & $14 \pm 0.48$ \\
\hline
\end{tabular}

Note: The minus (-) means no inhibition was observed.

The online version of the original article can be found at doi:http://dx.doi. org/10.1007/s00253-014-5572-3.

X. Wang $\cdot$ H. Wang $\cdot$ T. Liu $\cdot$ Z. Xin $(\bowtie)$

Key Laboratory of Food Processing and Quality Control, College of

Food Science and Technology, Nanjing Agricultural University,

Nanjing 210095, People's Republic of China

e-mail:xzhfood@njau.edu.cn 